Article

\title{
Anticoronaviral Activity of the Natural Phloroglucinols, Dryocrassin ABBA and Filixic Acid ABA from the Rhizome of Dryopteris crassirhizoma by Targeting the Main Protease of SARS-CoV-2
}

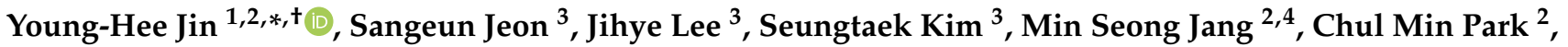 \\ Jong Hwan Song ${ }^{2}$, Hyoung Rae Kim ${ }^{2}$ and Sunoh Kwon ${ }^{2,5, *,+} \mathbb{D}$ \\ 1 KM Application Center, Korea Institute of Oriental Medicine, Daegu 41062, Korea \\ 2 Center for Convergent Research of Emerging Virus Infection, Korea Research Institute of Chemical \\ Technology, Daejeon 34114, Korea; minseongjang@kitox.re.kr (M.S.J.); parkcm@krict.re.kr (C.M.P.); \\ jhsong@krict.re.kr (J.H.S.); hyungrk@krict.re.kr (H.R.K.) \\ 3 Zoonotic Virus Laboratory, Institut Pasteur Korea, Seongnam 13488, Korea; sangeun.jeon@ip-korea.org (S.J.); \\ jihye.lee_01@ip-korea.org (J.L.); seungtaek.kim@ip-korea.org (S.K.) \\ 4 Department of Non-Clinical Studies, Korea Institute of Toxicology, Daejeon 34114, Korea \\ 5 KM Convergence Research Division, Korea Institute of Oriental Medicine, Daejeon 34054, Korea \\ * Correspondence: jinohee@kiom.re.kr (Y.-H.J.); sunohkwon@kiom.re.kr (S.K.); \\ Tel.: +82-42-610-8850 (Y.-H.J.); +82-42-868-9675 (S.K.) \\ + These authors contributed equally to this work.
}

check for updates

Citation: Jin, Y.-H.; Jeon, S.; Lee, J.; Kim, S.; Jang, M.S.; Park, C.M.; Song, J.H.; Kim, H.R.; Kwon, S.

Anticoronaviral Activity of the Natural Phloroglucinols, Dryocrassin ABBA and Filixic Acid ABA from the Rhizome of Dryopteris crassirhizoma by Targeting the Main Protease of SARS-CoV-2. Pharmaceutics 2022, 14, 376. https://doi.org/10.3390/ pharmaceutics 14020376

Academic Editor: Maria Nowakowska

Received: 26 December 2021

Accepted: 5 February 2022

Published: 8 February 2022

Publisher's Note: MDPI stays neutral with regard to jurisdictional claims in published maps and institutional affiliations.

Copyright: (c) 2022 by the authors Licensee MDPI, Basel, Switzerland. This article is an open access article distributed under the terms and conditions of the Creative Commons Attribution (CC BY) license (https:// creativecommons.org/licenses/by/ $4.0 /)$.

\begin{abstract}
The rhizome of Dryopteris crassirhizoma Nakai. (Dryopteridaceae) has been used in traditional medicine in East Asia and has recently been reported to have anticancer, anti-inflammation, and antibacterial activity as well as antiviral activity. Natural phloroglucinols from D. crassirhizoma, dryocrassin ABBA and filixic acid ABA were reported to inhibit influenza virus infection with an inhibitory activity on neuraminidase. In this study, we found that dryocrassin ABBA and filixic acid ABA have an inhibitory activity against the main protease of SARS-CoV-2. Therefore, dryocrassin ABBA and filixic acid ABA exhibited inhibitory activity against SARS-CoV-2 infection in Vero cells dose-dependently using the immunofluorescence-based antiviral assays. Moreover, these compounds inhibited SARS-CoV and MERS-CoV infection, suggesting their broad-spectrum anticoronaviral activity. In addition, a 5-day repeated-dose toxicity study of dryocrassin ABBA and filixic acid ABA suggested that an approximately lethal dose of these compounds in mice was $>10 \mathrm{mg} / \mathrm{kg}$. Pharmacokinetic studies of dryocrassin ABBA showed good microsomal stability, low hERG inhibition, and low CYP450 inhibition. In vivo pharmacokinetic properties of dryocrassin ABBA showed a long half-life (5.5-12.6 h) and high plasma exposure (AUC 19.3-65 $\mu \mathrm{g} \cdot \mathrm{h} / \mathrm{mL}$ ). Therefore, dryocrassin ABBA has therapeutic potential against emerging coronavirus infections, including COVID-19.
\end{abstract}

Keywords: Dryopteris crassirhizoma; dryocrassin ABBA; filixic acid ABA; coronavirus; SARS; MERS; COVID-19; antivirals; pharmacokinetics

\section{Introduction}

In spite of 8.4 billion doses of coronavirus disease 2019 (COVID-19) vaccines, approximately 274 million confirmed cases of COVID-19 and 5.3 million deaths were reported as of December 2021 by the World Health Organization during the global pandemic [1]. Clinically effective therapeutics are urgently needed to minimize the cases of critical patients.

Emerging human coronaviruses, SARS-CoV-2 as well as SARS-CoV and MERS-CoV, belong to the Coronaviridae family and Betacoronavirus genus [2]. SARS-CoV-2 consists of a $30 \mathrm{~kb}$ positive-sense, single-stranded RNA and structural proteins, such as the nucleocapsid, envelope, membrane, and spike proteins. The SARS-CoV-2 genome shares approximately 
79\% genomic sequence with SARS-CoV and 50\% with MERS-CoV [3]. Following SARSCoV-2 cell entry into host cells by the spike protein binding to the angiotensin-converting enzyme 2 receptor, the viral RNA encodes two polypeptides, namely ppla and pp1ab from two open reading frames, ORF1a and ORF1b, and four structural proteins [4]. The polyproteins are cleaved by the main protease (Mpro or 3CLpro) at 11 sites to generate numerous nonstructural proteins. This is an important step for viral replication [5].

Therefore, Mpro is considered an attractive target to inhibit viral replication $[6,7]$. Orally applicable viral protease inhibitors have been clinically used to treat hepatitis $C$ virus and human immunodeficiency virus infections [8,9]. Mpro is highly conserved between SARS-CoV and SARS-CoV-2, with approximately $96 \%$ homology of amino acid sequence [10]; therefore, variant resistance is less expected. SARS-CoV-2 Mpro is a cysteine protease and has substrate specificity, which is absent in the human protease, expecting less toxicity in humans [11]. To develop state-of-the-art antivirals for treating COVID-19, high throughput screening for SARS-CoV-2 Mpro inhibitors has been executed from a natural compound library.

The rhizome of Dryopteris crassirhizoma Nakai. (Dryopteridaceae) has been used as traditional medicine in East Asia and was recently reported to have anticancer [12], antiinflammatory [13], antibacterial [14], and anthelmintic [15] activity as well as antiviral activity against dengue virus [16]. It was reported that from $>20$ phloroglucinols isolated from $D$. crassirhizoma, dryocrassin ABBA and filixic acid ABA exhibited inhibitory activity against the neuraminidase of influenza virus and inhibited influenza virus infection [17].

In this study, we identified the SARS-CoV-2 Mpro inhibitory activity of natural phloroglucinols, dryocrassin ABBA and filixic acid ABA from the rhizome of $D$. crassirhizoma, before anticoronaviral activity against SARS-CoV, SARS-CoV-2, and MERS-CoV infections. In addition, we analyzed a 5-day repeated-dose toxicity study of these compounds and the pharmacokinetics of dryocrassin ABBA. Taken together, this study may provide the crucial information of potent natural compound inhibitors against the emerging coronavirus by targeting Mpro.

\section{Materials and Methods}

\subsection{Test Compounds}

Dryocrassin ABBA (PubChem ID 3082025, $\geq 98 \%$ purity) and filixic acid ABA (PubChem ID 15081408, $\geq 98 \%$ purity) were purchased from ChemFaces Biochemical Co. (Wuhan, China). Stock solutions (20 mM) were prepared in dimethyl sulfoxide (DMSO; Sigma-Aldrich, St. Louis, MO, USA). GC376 (BPS Bioscience, San Diego, CA, USA) were used as a positive control of Mpro activity assay in Mpro activity assay [18]. Lopinavir was purchased from SelleckChem (Houston, TX, USA) as a positive control [19] in immunofluorescence-based antiviral assay.

\subsection{SARS-CoV-2 Mpro Activity Assay}

SARS-CoV-2 Mpro activity was measured using the SARS-CoV-2 Mpro assay kit (BPS Bioscience, San Diego, CA, USA) according to the manufacturer's instructions. The samples were evaluated in duplicated, serially diluted concentrations. The fluorescence intensity of low binding, black, 96-well microtiter plates was detected at an excitation wavelength of $360 \mathrm{~nm}$ and an emission wavelength of $460 \mathrm{~nm}$ using a microplate spectrophotometer (Bio-Tek, Winooski, VT, USA).

\subsection{Cells and Viruses}

Vero (ATCC ${ }^{\circledR}$ CCL-81 ${ }^{\mathrm{TM}}$ ) cells were purchased from the American Type Culture Collection (ATCC; Manassas, VA, USA) and maintained in Dulbecco's modified Eagle's medium (DMEM; Gibco, Carlsbad, CA, USA) with 10\% fetal bovine serum (FBS; Gibco), and an antibiotic-antimycotic solution (Gibco) at $37{ }^{\circ} \mathrm{C}$ under $5 \% \mathrm{CO}_{2}$. The Korea Disease Control and Prevention Agency kindly provided SARS-CoV-2 ( $\beta \mathrm{CoV} / \mathrm{KOR} / \mathrm{KCDC03/2020)}$ and MERS-CoV (MERS-CoV/KOR/KNIH/002_05_2015) and Prof. J.S.M. Peiris from the 
University of Hong Kong kindly provided SARS-CoV (strain HK39849). Vero cells were used for virus propagation and plaque assays for titration. Experiments with SARS-CoV-2, SARS-CoV, and MERS-CoV were performed in a biosafety level-3 facility of the Institut Pasteur Korea (IP-K; Gyeonggi, Korea).

\subsection{Immunofluorescence-Based Antiviral Assays}

Vero cells $\left(1.2 \times 10^{4}\right.$ cells $)$ were cultured in DMEM with $1 \times$ antibiotic-antimycotic solution and $2 \%$ FBS in 384-well black culture plates. The serially diluted compounds and 0.0125 multiplicity of infection (MOI) SARS-CoV-2, 0.05 MOI SARS-CoV, or 0.0625 MOI MERS-CoV were added. At $24 \mathrm{~h}$ post-infection, the cells were fixed with $4 \%$ paraformaldehyde and stained with antibodies against the SARS-CoV-2 nucleocapsid protein, SARS-CoV spike protein, or MERS-CoV spike protein (Sino Biological Inc., Beijing, China), followed by goat antirabbit IgG secondary antibody and Hoechst 33342 (Thermo Fisher Scientific, Waltham, MA, USA). Images were analyzed using the Operetta ${ }^{\circledR}$ High-Content Imaging System (20×; PerkinElmer, Inc., Waltham, MA, USA) and Image-Mining 3.0 plug-in software [20].

\subsection{Five-Day Repeated-Dose Toxicity Study}

Five-week-old C57BL/6 mice (male and female) were purchased from Orient Bio, Inc. (Gyeonggi, Korea) and housed at the Animal Care Facility of the Korea Institute of Toxicology (KIT; Daejeon, Korea) under $24^{\circ} \mathrm{C}, 50 \%$ humidity, $12 \mathrm{~h}$ day/night cycle, and standard laboratory conditions. Mice were provided standard chow and drinking water and were acclimated for 7 days before the experiments. The experiments were approved by the Institutional Animal Care and Use Committee of KIT (approval number, KIT-B119020). The test compounds were intraperitoneally administrated at a dosage of $10 \mathrm{mg} / \mathrm{kg} / \mathrm{day}$ in a solution of DMSO:polyethylene glycol (PEG) 400:distilled water (DW) (5:40:55) for 5 days. Each treatment group had five male and five female mice. The mice were observed and their body weights were measured daily for 6 days.

\subsection{Liver Microsomal Metabolic Stability Assays}

Liver microsome samples $(0.5 \mathrm{mg}$ protein $/ \mathrm{mL})$ from mouse, rat, and human (Corning, Glendale, AZ, USA) in PBS and the test compound (final concentration $1 \mu \mathrm{M}$ ) were mixed. Following the addition of the NADPH regenerating solution (Corning), the samples were incubated at $37{ }^{\circ} \mathrm{C}$ for $30 \mathrm{~min}$. The reaction was stopped by the addition of ice-cold acetonitrile, and the samples were centrifuged at $4000 \mathrm{rpm}$ for $15 \mathrm{~min}$. The supernatant was analyzed using mass spectrometry with high-performance liquid chromatography (HPLC; Agilent Technologies, Santa Clara, CA, USA).

\subsection{Human Ether-a-Go-Go-Related Gene (hERG) $\mathrm{K}^{+}$Channel Activity Assays}

The hERG $\mathrm{K}^{+}$channel binding assay was performed with the HEK293 cell line expressing hERG using the automated planar patch clamp (PatchXpree 7000A) according to the manufacturer's instructions.

\subsection{Plasma Stability Assays}

Animal plasma (Innovative Research, Inc., Novi, MI, USA) and test compounds ( $5 \mu \mathrm{M})$ were incubated at $37^{\circ} \mathrm{C}$ for $4 \mathrm{~h}$. To prevent the reaction, cold acetonitrile was added. After the samples were centrifuged, the supernatant was analyzed using mass spectrometry with HPLC (Agilent Technologies).

\subsection{Cytochrome P-450 (CYP450) Enzyme Inhibition Assays}

Human liver microsomes $(0.2 \mathrm{mg}$ protein $/ \mathrm{mL})$ were mixed with the test compound at $37{ }^{\circ} \mathrm{C}$ for $5 \mathrm{~min}$. NADPH Regenerating solution (Corning) and specific substrates, namely phenacetin (CYP1A2, Sigma-Aldrich), tolbutamide (CYP2C9, Sigma-Aldrich), Smephenytoin (CYP2C19, Corning), dextromethorphan (CYP2D6, Sigma-Aldrich), and 
sorafenib (CYP3A4, Santa Cruz Biotechnology, Inc., Dallas, TX, USA) were added and incubated at $37{ }^{\circ} \mathrm{C}$ for $30 \mathrm{~min}$. Cold acetonitrile was added and the supernatant was analyzed using mass spectrometry with HPLC (Agilent Technologies).

\subsection{Pharmacokinetic Studies in Mice}

Seven-week-old male ICR mice were purchased from Nara Bio Co., Ltd. (Pyungtaek, Korea) and housed under $24^{\circ} \mathrm{C}, 50 \%$ humidity, and $12 \mathrm{~h}$ day/night cycle conditions with access to standard chow and drinking water. Mice were acclimated for 1 week before the experiments. All animal procedures were approved by the KRICT Animal Care and Use Committee (ACUC approval number, DDP-7221). A total of $10 \mathrm{mg} / \mathrm{kg}$ of compound in a 5:40:55 ratio of DMSO:PEG400:DW was intraperitoneally or orally administered $(n=3)$. Blood samples were collected at 0.083-24 h after drug administration through the retroorbital venous plexus and the plasma fraction was separated by centrifugation $(15,000 \mathrm{rpm}$, $3 \mathrm{~min}$ ). Following the addition of 9 volumes of acetonitrile to the plasma samples and centrifugation $\left(13,000 \mathrm{rpm}, 10 \mathrm{~min}\right.$ at $\left.4^{\circ} \mathrm{C}\right)$, the supernatant was analyzed using mass spectrometry with HPLC (Agilent Technologies). Mean plasma concentration-time data were calculated using noncompartmental methods (Phoenix WinNonlin software version 6.4; Pharsight Corporation, Mountain View, CA, USA).

\subsection{Statistical Analysis}

Data were presented as the mean \pm standard error of the mean of at least two independent experiments. Non-linear regression analysis of the half-maximal inhibitory concentration $\left(\mathrm{IC}_{50}\right)$ was conducted using GraphPad Prism ${ }^{\circledR}$ Software version 6.05 for Windows (GraphPad Software Inc., San Diego, CA, USA).

\section{Results}

\subsection{SARS-CoV-2 Mpro Inhibitory Activity of Dryocrassin ABBA and Filixic Acid ABA}

To identify the inhibitor of SARS-CoV-2 Mpro, the natural compounds were screened using the SARS-CoV-2 Mpro assay kit. Among the screened compounds, dryocrassin ABBA and filixic acid ABA (Figure 1), which are the phloroglucinols from the rhizome of D. crassirhizoma, inhibited Mpro activity in a dose-dependent manner. Data showed that the $\mathrm{IC}_{50}$ values of dryocrassin $\mathrm{ABBA}$ and filixic acid ABA were $46.48 \pm 1.1 \mu \mathrm{M}$ and $39.63 \pm 1.09 \mu \mathrm{M}$, respectively (Figure 2). These data suggest that dryocrassin ABBA and filixic acid ABA have a similar phloroglucinol structure and similar inhibitory activity against SARS-CoV-2 Mpro.

A.

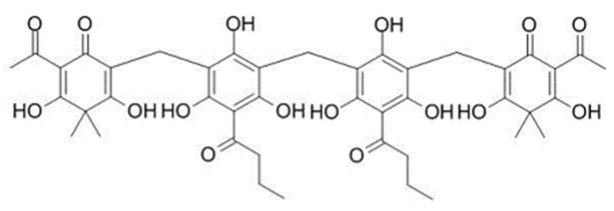

B.

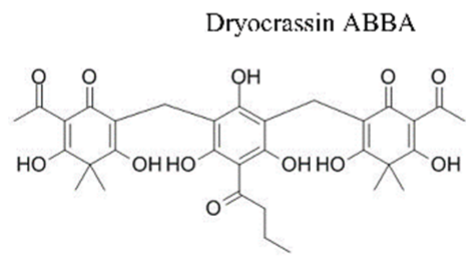

Filixic acid $\mathrm{ABA}$

Figure 1. Chemical structure of dryocrassin ABBA (A) and filixic acid ABA (B). 
A.
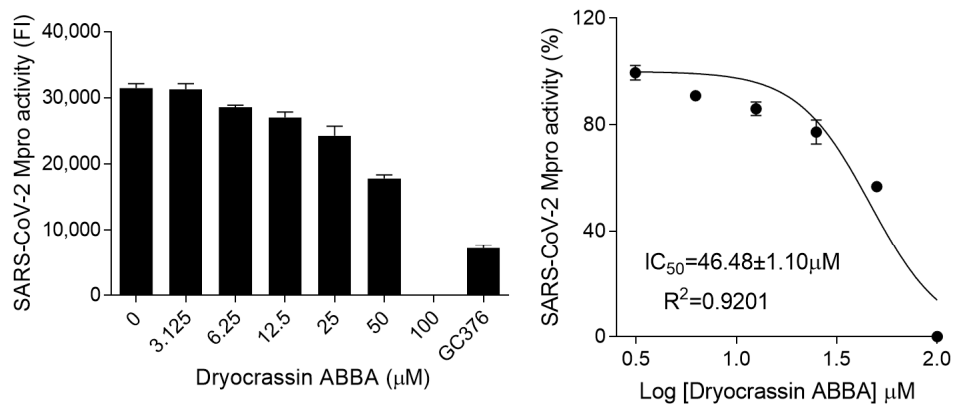

B.
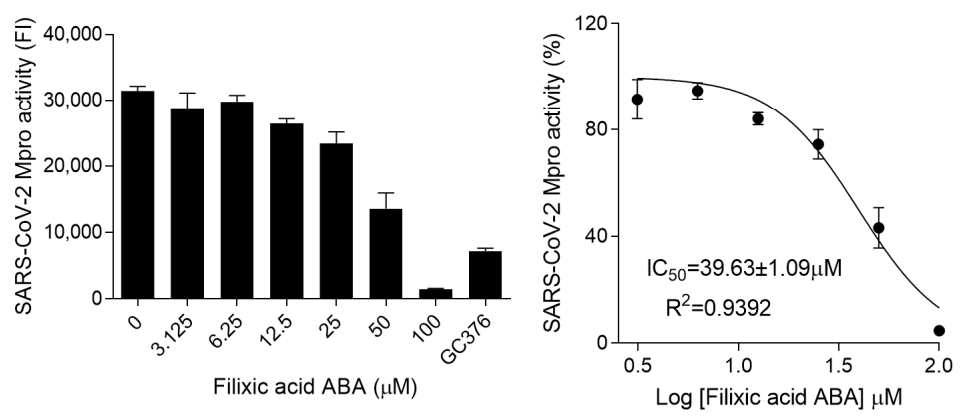

Figure 2. Inhibition of SARS-CoV-2 3CL activities of dryocrassin ABBA and filixic acid ABA (A,B). Dose-dependent inhibition of dryocrassin ABBA (A) and filixic acid ABA (B) in SARS-CoV-2 3CL activity analysis was shown with serially diluted compounds (3.125-100 $\mu \mathrm{M})$. We used $100 \mu \mathrm{M}$ GC376 as the positive control. $\mathrm{IC}_{50}$ values were calculated using non-linear regression analysis. The data are presented as the mean \pm SEM of at least duplicate experiments.

\subsection{Anti-SARS-CoV-2 Activity of Dryocrassin ABBA and Filixic Acid ABA}

We examined the anti-SARS-CoV-2 activity of dryocrassin ABBA and filixic acid ABA due to their inhibitory activity against SARS-CoV-2 Mpro. Immunofluorescence-based antiviral assays were performed in 0.0125 MOI SARS-CoV-2 infected Vero cells treated with a serially diluted concentration of these compounds by staining SARS-CoV-2 nucleocapsid antigen at $24 \mathrm{~h}$ after infection (Figure $3 \mathrm{~A}$ ). The $\mathrm{IC}_{50}$ value of each compound was calculated using non-linear regression analysis. Our data revealed that the $\mathrm{IC}_{50}$ values of dryocrassin ABBA and filixic acid ABA were $22.40 \pm 0.73 \mu \mathrm{M}$ and $25.90 \pm 0.81 \mu \mathrm{M}$, respectively, with $\mathrm{CC}_{50}$ values of $>50 \mu \mathrm{M}$ (Figure $3 \mathrm{~B}$ ). These data suggest that these compounds had antiSARS-CoV-2 activity, with similar $\mathrm{IC}_{50}$ values, through their inhibitory activity against SARS-CoV-2 Mpro.

\subsection{Broad-Spectrum Anticoronaviral Activity of Dryocrassin ABBA and Filixic Acid ABA}

To investigate whether these compounds have inhibitory activity against other coronaviruses, immunofluorescence-based antiviral assays were performed in 0.05 MOI SARS$\mathrm{CoV}$ or $0.0625 \mathrm{MOI}$ MERS-CoV-infected Vero cells treated with a serially diluted concentration of these compounds by detecting SARS-CoV spike protein or MERS-CoV spike protein, respectively, at $24 \mathrm{~h}$ post-infection (Figure S1). Our findings revealed that dryocrassin ABBA and filixic acid ABA inhibited SARS-CoV infection with an $\mathrm{IC}_{50}$ of $0.80 \pm 0.07 \mu \mathrm{M}$ and $\mathrm{IC}_{50} 4.56 \pm 0.21 \mu \mathrm{M}$, respectively, (Figure $3 \mathrm{C}$ ). In addition, dryocrassin ABBA and filixic acid ABA inhibited MERS-CoV infection with $\mathrm{IC}_{50} 1.31 \pm 0.07 \mu \mathrm{M}$ and $\mathrm{IC}_{50} 2.67 \pm 0.10 \mu \mathrm{M}$, respectively (Figure 3D). These data suggest that dryocrassin ABBA and filixic acid ABA have broad-spectrum, anticoronaviral activity, and dryocrassin ABBA has better antiviral activity with a lower $\mathrm{IC}_{50}$ than filixic acid ABA. 

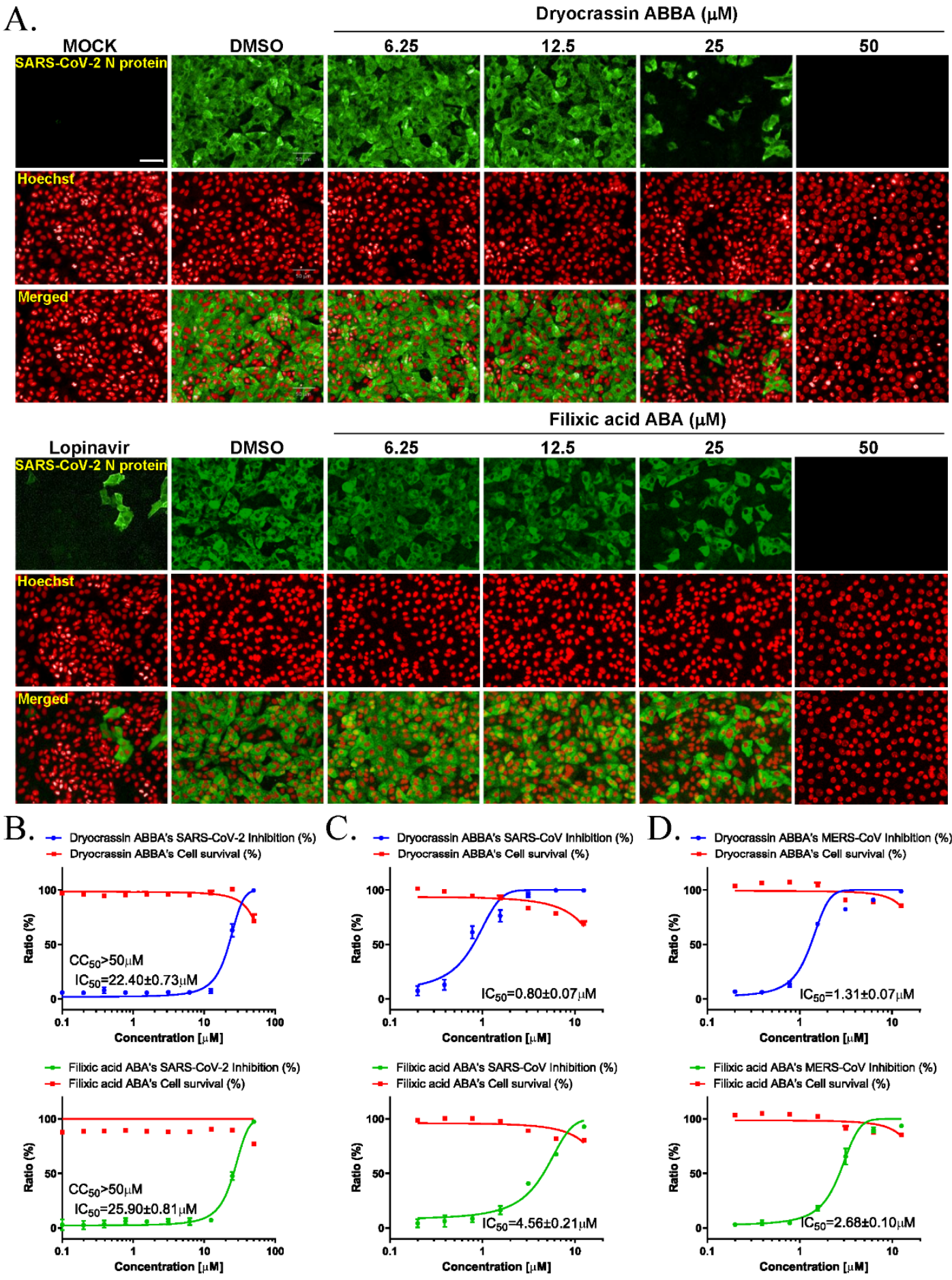

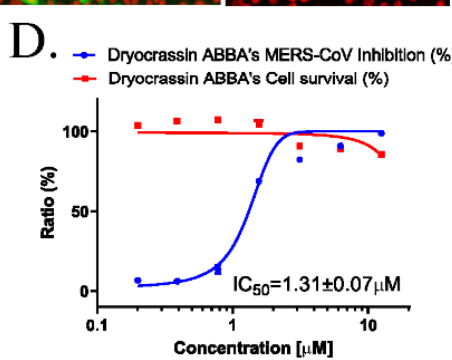

$\rightarrow$ Filixic acid ABA's MERS-CoV Inhibition (\%) - Filixic acid ABA's Cell survival (\%)

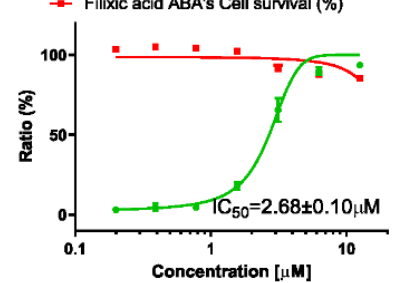

Figure 3. Anticoronaviral activities of dryocrassin ABBA and filixic acid ABA. (A) The confocal microscope images presented SARS-CoV-2 nucleocapsid (N) protein (green), cell nuclei (Hoechst, red) at the indicated concentrations of dryocrassin ABBA or filixic acid ABA, or 6.25 $\mu \mathrm{M}$ lopinavir after SARS$\mathrm{CoV}-2$ infection. Scale bar $=50 \mu \mathrm{m}(\mathrm{B}-\mathrm{D})$ Dose-response curve analysis using immunofluorescence staining was performed to determine the anti-SARS-COV-2 (B), SARS-CoV (C), or MERS-CoV (D) effect of dryocrassin ABBA (left panel) and filixic acid ABA (right panel) in virus-infected Vero cells. The inhibition of virus infection (\%; blue circles for dryocrassin ABBA and green circles for filixic acid $\mathrm{ABA}$ ) and cell viability (\%; red squares) are indicated. $\mathrm{IC}_{50}$ values were calculated using non-linear regression analysis. The data are presented as the mean \pm SEM of at least duplicate experiments. 


\subsection{Five-Day Repeated-Dose Toxicity of Dryocrassin ABBA and Filixic Acid ABA}

To evaluate the potential systemic toxicity of dryocrassin ABBA and filixic acid ABA, 5-day repeated-dose toxicity studies were conducted through IP administration of $10 \mathrm{mg} / \mathrm{kg}$ to male and female mice (each $\mathrm{n}=5$ ). No abnormal clinical signs and animal death were observed for 6 days after the IP administration of the compounds (Figure 4). Although the body weight was reduced at 2 day-post administration by $10 \%$, it completely recovered 4 days post-administration of dryocrassin ABBA and filixic acid ABA. These data suggest that the approximately lethal dose of dryocrassin ABBA and filixic acid ABA in male and female mice was more than $10 \mathrm{mg} / \mathrm{kg}$.

A.

B.
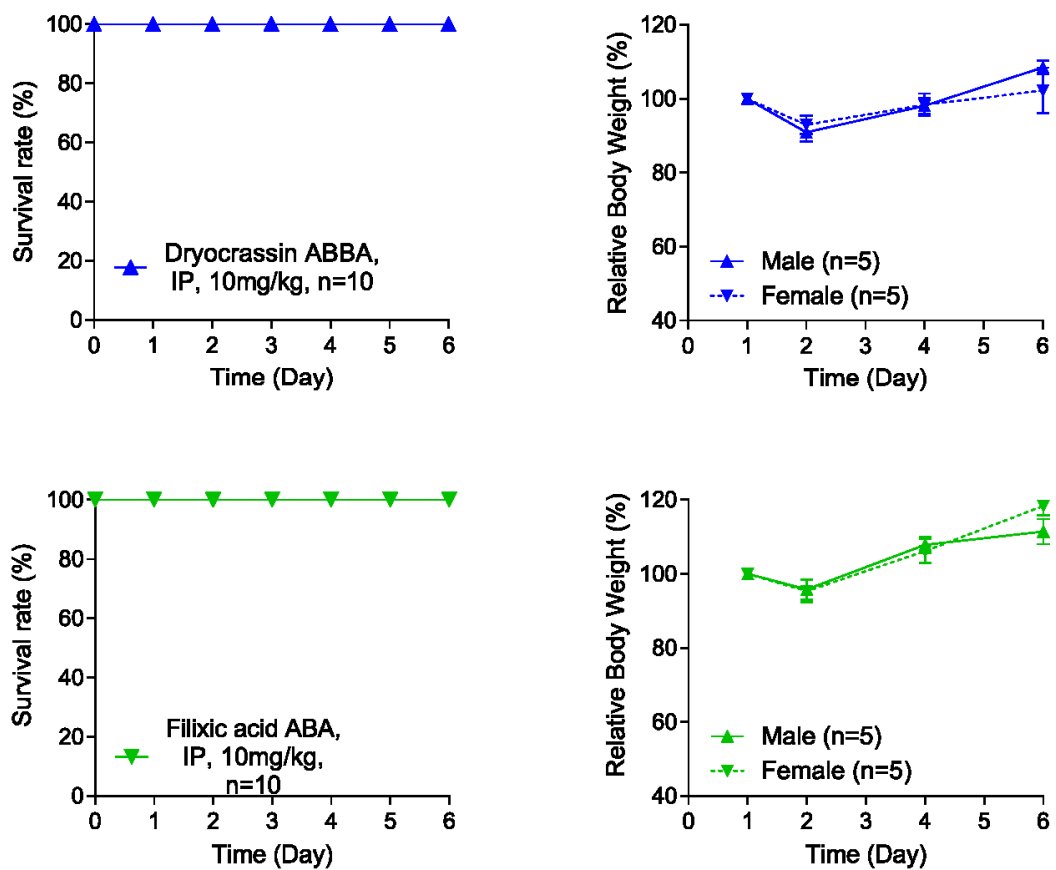

Figure 4. Five-day repeated-dose toxicity of dryocrassin ABBA and filixic acid ABA. (A,B) Survival rate (left panel) and body weight changes (right panel) in male ( $n=5 /$ group) and female ( $n=5$ /group) mice intraperitoneally administrated dryocrassin ABBA (A) and filixic acid ABA (B) at $10 \mathrm{mg} / \mathrm{kg} /$ day for 5 days.

\subsection{Pharmacokinetics of Dryocrassin ABBA}

Dryocrassin ABBA was selected to further investigate the pharmacological features such as liver microsomal stability, hERG inhibition, plasma stability, and CYP450 inhibition (Table 1). Dryocrassin ABBA was examined against mouse, rat, and human liver microsomes. It was well tolerated in mouse, rat, and human liver microsomes, with more than $68 \%$ remaining after $30 \mathrm{~min}$ incubation. In the $\mathrm{hERG}$ patch clamp assay, the $\mathrm{IC}_{50}$ value of dryocrassin ABBA on hERG potassium channel was less than $50 \mu \mathrm{M}$ and the inhibition percentage was $7.27 \%$ at $10 \mu \mathrm{M}$, suggesting the cardiac safety of dryocrassin ABBA. Plasma stability of dryocrassin ABBA was lower in the human model $(29.67 \% \pm 8.37 \%$ remaining) than in the rat model $(67 \% \pm 7.29 \%$ remaining). The CYP450 inhibition assay data revealed that the $\mathrm{IC}_{50}$ values of dryocrassin $\mathrm{ABBA}$ were $8.33-16.1 \mu \mathrm{M}$ on isozymes, except for $0.4 \mu \mathrm{M} \mathrm{IC}_{50}$ on $2 \mathrm{C} 9$ isozyme. Finally, we analyzed the in vivo pharmacokinetic (PK) properties of $10 \mathrm{mg} / \mathrm{kg}$ dryocrassin ABBA in mice $(\mathrm{n}=3)$ by intraperitoneal (IP) and oral (PO) administration (Figure 5 and Table 2). The half-life of the compound via IP was $5.5 \mathrm{~h}$ and the AUC value was $65 \mu \mathrm{g} \cdot \mathrm{h} / \mathrm{mL}$. In the case of $\mathrm{PO}$ administration, the half-life of the compound was $12.6 \mathrm{~h}$ and the $C_{\max }$ value was $3.64 \mu \mathrm{g} / \mathrm{mL}$, reflecting $19.3 \mu \mathrm{g} \cdot \mathrm{h} / \mathrm{mL}$ 
AUC. These data suggest that dryocrassin ABBA is an acceptable candidate as a COVID-19 therapeutic drug.

Table 1. Microsomal stability (MS), hERG inhibition, plasma stability $(5 \mu \mathrm{M})$, and cytochrome P450 (CYP450) inhibition of dryocrassin ABBA.

\begin{tabular}{|c|c|c|c|c|c|c|c|c|c|c|}
\hline \multicolumn{3}{|c|}{$\begin{array}{c}\text { MS (\%) } \\
\text { (Remaining after } 30 \mathrm{~min} \text { ) }\end{array}$} & \multirow[t]{2}{*}{$\begin{array}{l}\text { hERG } \\
\text { Inhibition }\end{array}$} & \multicolumn{2}{|c|}{$\begin{array}{l}\text { Plasma Stability } \\
\text { (\% Remaining) }\end{array}$} & \multicolumn{5}{|c|}{ CYP450 Inhibition $\left(\mathrm{IC}_{50}, \mu \mathrm{M}\right)$} \\
\hline Mice & Rat & Hum & & Hum & Rat & 1A2 & 2C9 & 2C19 & 2D6 & $3 \mathrm{~A} 4$ \\
\hline $68.3 \pm 2.1$ & $>99$ & $>99$ & $\begin{array}{l}7.27 \%(10 \mu \mathrm{M}) \\
\mathrm{IC}_{50}>50 \mu \mathrm{M}\end{array}$ & $29.67 \pm 8.37$ & $67.00 \pm 7.29$ & 14.7 & 0.4 & 16.1 & 13.5 & 8.33 \\
\hline
\end{tabular}

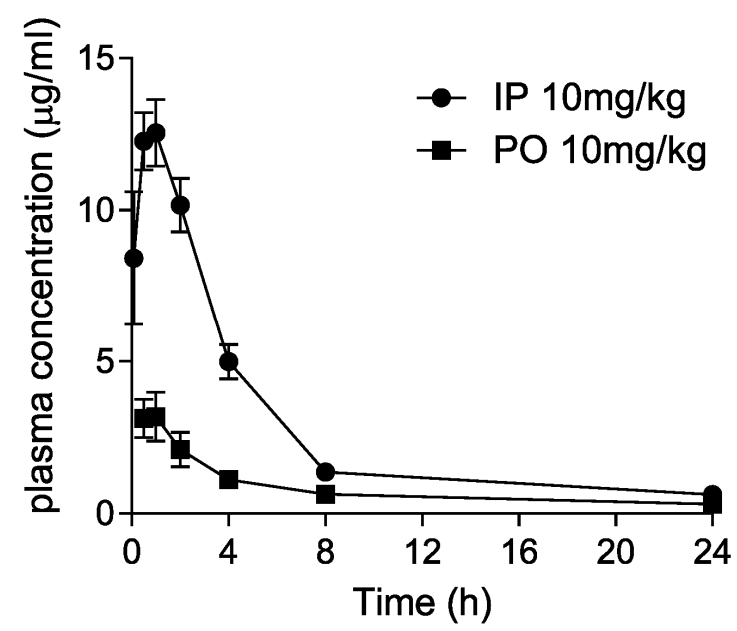

Figure 5. Pharmacokinetic plasma concentration-time curves following intraperitoneal (IP) and oral (PO) administration of $10 \mathrm{mg} / \mathrm{kg}$ dryocrassin ABBA in mice.

Table 2. Mouse pharmacokinetic study of dryocrassin ABBA.

\begin{tabular}{ccc}
\hline Parameters $(\mathbf{n}=\mathbf{3})$ & IP $(\mathbf{1 0} \mathbf{~ m g} / \mathbf{k g})$ & PO $\mathbf{( 1 0 ~} \mathbf{~ g} / \mathbf{k g})$ \\
\hline $\mathrm{T}_{\max }(\mathrm{h})$ & $1.17 \pm 0.76$ & $0.67 \pm 0.29$ \\
$\mathrm{C}_{\max }(\mu \mathrm{g} / \mathrm{mL})$ & $12.81 \pm 1.79$ & $3.64 \pm 0.57$ \\
$\mathrm{~T}_{1 / 2}(\mathrm{~h})$ & $5.5 \pm 0.56$ & $12.6 \pm 3.76$ \\
$\mathrm{AUC}(\mu \mathrm{g} \cdot \mathrm{h} / \mathrm{mL})$ & $65.96 \pm 8.63$ & $19.3 \pm 1.42$ \\
\hline
\end{tabular}

\section{Discussion}

The rhizome of $D$. crassirhizoma is used as traditional medicine against inflammation. The rhizome of D. crassirhizoma is one of the main components of the Lianhua-Qingwen formula, which is composed of 11 herbal medicines traditionally used for heat-clearing and detoxifying, recently used for the prevention and treatment of viral influenza [21,22], SARS, and COVID-19 in China [23,24].

Among the constituents derived from the rhizome of D. crassirhizoma, kaempferol glycosides have been known to have inhibitory activity on human immunodeficiency virus reverse transcriptase [25]; hopane-type triterpenes are also reported to have an inhibitory activity on human immunodeficiency virus protease [26]. Flavaspidic acid AB compound from $D$. crassirhizoma inhibited the replication of porcine reproductive and respiratory syndrome virus by inhibiting virus internalization and inducing antiviral cytokines [27]. Moreover, phloroglucinols from D. crassirhizoma, dryocrassin ABBA and filixic acid ABA exhibited inhibitory effects on the NA of H5N1 influenza virus with an $\mathrm{IC}_{50}$ of $18.59 \pm 4.53$ and $29.57 \pm 2.48 \mu \mathrm{M}$, respectively; however, only dryocrassin ABBA exhibited anti-influenza virus activity with an $\mathrm{IC}_{50}$ of $16.5 \mu \mathrm{M}$ and filixic acid ABA with $<50 \%$ at $100 \mu \mathrm{M}$ [17]. 
Our findings revealed that two phloroglucinols isolated from D. crassirhizoma, dryocrassin ABBA and filixic acid ABA, have dose-dependent inhibitory activity against the Mpro of SARS-CoV-2 virus, which may result in preventing the cleavage of coronaviral polypeptides, pp1a and pp1ab, into nonstructural proteins for viral replication [5]. Ultimately, these compounds inhibited SARS-CoV-2 virus infection as well as other coronavirus infections, including SARS-CoV and MERS-CoV due to the highly conserved homology among coronaviral Mpros [10]. These data suggest that it is possible to develop dryocrassin ABBA and filixic acid ABA as a potent broad-spectrum anticoronaviral therapeutic drug, including COVID-19 by direct acting antivirals targeting the Mpro.

For drug development, a 5-day repeated-dose toxicity study of dryocrassin ABBA and filixic acid $A B A$ helped identify that the approximately lethal dose of dryocrassin ABBA and filixic acid ABA in mice was $>10 \mathrm{mg} / \mathrm{kg}$. Pharmacological assays, such as liver microsomal stability assay, hERG inhibition assay, plasma stability assay, and the CYP450 inhibition assay of dryocrassin ABBA suggested good stability, low hERG channel inhibition, and low CYP450 inhibition, except for 2C9 isozyme activity. Investigations of the in vivo pharmacokinetic properties of dryocrassin ABBA showed a long half-life and high plasma exposure. Pharmacodynamic study and in vivo proof of concept would be necessary in future study.

\section{Conclusions}

We found that natural phloroglucinols, dryocrassin ABBA, and filixic acid ABA, play a role in the inhibition of SARS-CoV-2 infection by inhibiting the Mpro of SARS-CoV-2 as well as have broad-spectrum anti-emerging coronaviral activity. Furthermore, the preclinical studies on the toxicity and pharmacokinetics of dryocrassin ABBA suggested that dryocrassin ABBA is a promising therapeutic candidate for the development of anticoronaviral drugs, including those against COVID-19.

Supplementary Materials: The following are available online at https:/ /www.mdpi.com/article/10 .3390/pharmaceutics14020376/s1, Figure S1: The confocal microscope images showing the SARS$\mathrm{CoV}$ spike (S) protein (green) (A), MERS-CoV spike (S) protein (green) (B), and cell nuclei (Hoechst, red) at the indicated concentration of each compound or $25 \mu \mathrm{M}$ lopinavir after SARS-CoV (A) or MERS-CoV (B) infection.

Author Contributions: Conceptualization, Y.-H.J. and S.K. (Sunoh Kwon); methodology, Y.-H.J. and S.K. (Sunoh Kwon); validation, Y.-H.J., S.J., J.L., S.K. (Seungtaek Kim), M.S.J., C.M.P., J.H.S., H.R.K., and S.K. (Sunoh Kwon); formal analysis, Y.-H.J. and S.K. (Sunoh Kwon); investigation, Y.-H.J., S.J., J.L., M.S.J., C.M.P., and S.K. (Sunoh Kwon); resources, H.R.K. and S.K. (Sunoh Kwon); data curation, Y.-H.J., S.J., J.L., M.S.J., and S.K. (Sunoh Kwon); writing—original draft preparation, Y.-H.J. and S.K. (Sunoh Kwon); writing—review and editing, Y.-H.J. and S.K. (Sunoh Kwon); visualization, Y.-H.J. and S.K. (Sunoh Kwon); supervision, Y.-H.J. and S.K. (Sunoh Kwon); project administration, Y.-H.J. and S.K. (Sunoh Kwon); funding acquisition, S.K. (Sunoh Kwon). All authors have read and agreed to the published version of the manuscript.

Funding: This study was supported by the National Research Council of Science \& Technology (NST) grant (grant numbers CRC-16-01-KRICT-03, NSN1623461, CAP20012-110 and NSN2012460) and the Korea Institute of Oriental Medicine (grant number KSN2022220) funded by the Korea government (MSIT).

Institutional Review Board Statement: This study was approved by the Institutional Animal Care and Use Committee of KIT (approval number, KIT-B119020) and by that of KRICT (approval number, DDP-7221).

Informed Consent Statement: Not applicable.

Data Availability Statement: The data presented in this study are available in this article.

Acknowledgments: The pathogen resource (NCCP43326) for this study was provided by the National Culture Collection for Pathogens. 
Conflicts of Interest: The authors declare no conflict of interest. The funders had no role in the design of the study; in the collection, analyses, or interpretation of data; in the writing of the manuscript, or in the decision to publish the results.

$\begin{array}{ll}\text { Abbreviations } \\ \text { 3CLpro } & \text { 3C-like protease } \\ \text { CC }_{50} & \text { Half-maximal cytotoxic concentration } \\ \text { CoV } & \text { Coronavirus } \\ \text { COVID-19 } & \text { Coronavirus disease 2019 } \\ \text { CYP450 } & \text { Cytochrome P-450 } \\ \text { hERG } & \text { Human ether-a-go-go-related gene } \\ \text { IC }_{50} & \text { Half-maximal inhibitory concentration } \\ \text { MERS-CoV } & \text { Middle East respiratory syndrome coronavirus } \\ \text { Mpro } & \text { Main protease } \\ \text { NA } & \text { Neuraminidase } \\ \text { ORF } & \text { Open reading frame } \\ \text { SARS-CoV } & \text { Severe acute respiratory syndrome coronavirus } \\ \text { SARS-CoV-2 } & \text { Severe acute respiratory syndrome coronavirus 2 }\end{array}$

\section{References}

1. World Health Organization. Coronavirus Disease (COVID-19) Pandemic. Available online: https://covid19.who.int/ (accessed on 21 December 2021)

2. V'kovski, P.; Kratzel, A.; Steiner, S.; Stalder, H.; Thiel, V. Coronavirus biology and replication: Implications for SARS-CoV-2. Nat. Rev. Microbiol. 2021, 19, 155-170. [CrossRef]

3. Zhou, P.; Yang, X.-L.; Wang, X.-G.; Hu, B.; Zhang, L.; Zhang, W.; Si, H.-R.; Zhu, Y.; Li, B.; Huang, C.-L. A pneumonia outbreak associated with a new coronavirus of probable bat origin. Nature 2020, 579, 270-273. [CrossRef] [PubMed]

4. Hu, B.; Guo, H.; Zhou, P.; Shi, Z.L. Characteristics of SARS-CoV-2 and COVID-19. Nat. Rev. Microbiol. 2021, 19, 141-154. [CrossRef] [PubMed]

5. Kim, D.; Lee, J.Y.; Yang, J.S.; Kim, J.W.; Kim, V.N.; Chang, H. The Architecture of SARS-CoV-2 Transcriptome. Cell 2020, 181, 914-921.e910. [CrossRef]

6. Owen, D.R.; Allerton, C.M.; Anderson, A.S.; Aschenbrenner, L.; Avery, M.; Berritt, S.; Boras, B.; Cardin, R.D.; Carlo, A.; Coffman, K.J. An oral SARS-CoV-2 Mpro inhibitor clinical candidate for the treatment of COVID-19. Science 2021, 374, 1586-1593.

7. Breidenbach, J.; Lemke, C.; Pillaiyar, T.; Schäkel, L.; Al Hamwi, G.; Diett, M.; Gedschold, R.; Geiger, N.; Lopez, V.; Mirza, S Targeting the Main Protease of SARS-CoV-2: From the Establishment of High Throughput Screening to the Design of Tailored Inhibitors. Angew. Chem. Int. Ed. 2021, 60, 10423-10429. [CrossRef]

8. Suda, G.; Sakamoto, N. Recent advances in the treatment of hepatitis C virus infection for special populations and remaining problems. J. Gastroenterol. Hepatol. 2021, 36, 1152-1158. [CrossRef] [PubMed]

9. Voshavar, C. Protease Inhibitors for the Treatment of HIV/AIDS: Recent Advances and Future Challenges. Curr. Top. Med. Chem. 2019, 19, 1571-1598. [CrossRef]

10. Hattori, S.-i.; Higashi-Kuwata, N.; Hayashi, H.; Allu, S.R.; Raghavaiah, J.; Bulut, H.; Das, D.; Anson, B.J.; Lendy, E.K.; Takamatsu, Y. A small molecule compound with an indole moiety inhibits the main protease of SARS-CoV-2 and blocks virus replication. Nat. Commun. 2021, 12, 1-12. [CrossRef]

11. Rut, W.; Groborz, K.; Zhang, L.; Sun, X.; Zmudzinski, M.; Pawlik, B.; Wang, X.; Jochmans, D.; Neyts, J.; Młynarski, W. SARS-CoV-2 M pro inhibitors and activity-based probes for patient-sample imaging. Nat. Chem. Biol. 2021, 17, 222-228. [CrossRef] [PubMed]

12. Lee, J.; Nho, Y.H.; Yun, S.K.; Hwang, Y.S. Anti-invasive and Anti-tumor Effects of Dryopteris crassirhizoma Extract by Disturbing Actin Polymerization. Integr. Cancer 2019, 18, 1534735419851197. [CrossRef] [PubMed]

13. Yang, Y.; Lee, G.J.; Yoon, D.H.; Yu, T.; Oh, J.; Jeong, D.; Lee, J.; Kim, S.H.; Kim, T.W.; Cho, J.Y. ERK1- and TBK1-targeted anti-inflammatory activity of an ethanol extract of Dryopteris crassirhizoma. J. Ethnopharmacol 2013, 145, 499-508. [CrossRef] [PubMed]

14. Ban, S.H.; Kim, J.E.; Pandit, S.; Jeon, J.G. Influences of Dryopteris crassirhizoma extract on the viability, growth and virulence properties of Streptococcus mutans. Molecules 2012, 17, 9231-9244. [CrossRef] [PubMed]

15. Jiang, B.; Chi, C.; Fu, Y.W.; Zhang, Q.Z.; Wang, G.X. In vivo anthelmintic effect of flavonol rhamnosides from Dryopteris crassirhizoma against Dactylogyrus intermedius in goldfish (Carassius auratus). Parasitol. Res. 2013, 112, 4097-4104. [CrossRef]

16. Maryam, M.; Te, K.K.; Wong, F.C.; Chai, T.T.; Gary, K.; Gan, S.C. Antiviral activity of traditional Chinese medicinal plants Dryopteris crassirhizoma and Morus alba against dengue virus. J. Integr. Agric. 2020, 19, 1085-1096. [CrossRef]

17. Wang, J.; Yan, Y.T.; Fu, S.Z.; Peng, B.; Bao, L.L.; Zhang, Y.L.; Hu, J.H.; Zeng, Z.P.; Geng, D.H.; Gao, Z.P. Anti-Influenza Virus (H5N1) Activity Screening on the Phloroglucinols from Rhizomes of Dryopteris crassirhizoma. Molecules 2017, 22, 431. [CrossRef] 
18. Fu, L.; Ye, F.; Feng, Y.; Yu, F.; Wang, Q.; Wu, Y.; Zhao, C.; Sun, H.; Huang, B.; Niu, P.; et al. Both Boceprevir and GC376 efficaciously inhibit SARS-CoV-2 by targeting its main protease. Nat. Commun. 2020, 11, 4417. [CrossRef]

19. Sheahan, T.P.; Sims, A.C.; Leist, S.R.; Schafer, A.; Won, J.; Brown, A.J.; Montgomery, S.A.; Hogg, A.; Babusis, D.; Clarke, M.O.; et al. Comparative therapeutic efficacy of remdesivir and combination lopinavir, ritonavir, and interferon beta against MERS-CoV. Nat. Commun. 2020, 11, 222. [CrossRef]

20. Jin, Y.H.; Min, J.S.; Jeon, S.; Lee, J.; Kim, S.; Park, T.; Park, D.; Jang, M.S.; Park, C.M.; Song, J.H.; et al. Lycorine, a non-nucleoside RNA dependent RNA polymerase inhibitor, as potential treatment for emerging coronavirus infections. Phytomedicine 2021, 86, 153440. [CrossRef]

21. Wu, L.; Chen, Y.; Ma, Y.; Yang, Z.; Yang, N.; Deng, W.; Chen, Y.; Sun, Y.; Li, Y.; Lin, L. Clinical practice guideline on treating influenza in adult patients with Chinese patent medicines. Pharmacol. Res. 2020, 160, 105101. [CrossRef]

22. Gao, D.; Niu, M.; Wei, S.-Z.; Zhang, C.-e.; Zhou, Y.-f.; Yang, Z.-w.; Li, L.; Wang, J.-b.; Zhang, H.-Z.; Zhang, L. Identification of a pharmacological biomarker for the bioassay-based quality control of a thirteen-component TCM formula (Lianhua Qingwen) used in treating influenza A virus (H1N1) infection. Front. Pharmacol. 2020, 11, 746. [CrossRef] [PubMed]

23. Fan, A.Y.; Gu, S.; Alemi, S.F. Chinese herbal medicine for COVID-19: Current evidence with systematic review and meta-analysis. J. Integr. Med. 2020, 18, 385. [CrossRef] [PubMed]

24. Runfeng, L.; Yunlong, H.; Jicheng, H.; Weiqi, P.; Qinhai, M.; Yongxia, S.; Chufang, L.; Jin, Z.; Zhenhua, J.; Haiming, J.; et al. Lianhuaqingwen exerts anti-viral and anti-inflammatory activity against novel coronavirus (SARS-CoV-2). Pharm. Res. 2020, 156, 104761. [CrossRef] [PubMed]

25. Min, B.S.; Tomiyama, M.; Ma, C.M.; Nakamura, N.; Hattori, M. Kaempferol acetylrhamnosides from the rhizome of Dryopteris crassirhizoma and their inhibitory effects on three different activities of human immunodeficiency virus-1 reverse transcriptase. Chem. Pharm. Bull. 2001, 49, 546-550. [CrossRef] [PubMed]

26. Lee, J.S.; Miyashiro, H.; Nakamura, N.; Hattori, M. Two new triterpenes from the Rhizome of Dryopteris crassirhizoma, and inhibitory activities of its constituents on human immunodeficiency virus-1 protease. Chem. Pharm. Bull. 2008, 56, 711-714. [CrossRef] [PubMed]

27. Yang, Q.; Gao, L.; Si, J.; Sun, Y.; Liu, J.; Cao, L.; Feng, W.H. Inhibition of porcine reproductive and respiratory syndrome virus replication by flavaspidic acid AB. Antivir. Res. 2013, 97, 66-73. [CrossRef] 